\title{
Aromatherapy in the Control of Stress and Anxiety
}

Dias Paula ${ }^{1}$, Pedro Luís ${ }^{2}$, Pereira Olívia $\mathbf{R}^{3^{*}}$ and Sousa Maria João ${ }^{1 *}$

${ }^{1}$ Country Research Center, Higher Agricultural School, Polytechnic Institute of Bragança, Campus of Santa Apolónia, Apartado 1172, 5301-855, Bragança, Portugal

${ }^{2}$ Center for Environmental and Sea Studies Lisbon, Faculty of Sciences, University of Lisbon, CBV, DBV, 1749-016, Lisboa, Portugal

${ }^{3}$ Departamento of Diagnostic and Therapeutic Technology, School of Health, Polytechnic Institute of Bragança, Av. D. Afonso V, 5300-121, Bragança, Portugal

*Corresponding authors:Sousa Maria João, Country Research Center, Higher Agricultural School, Polytechnic Institute of Bragança, Campus of Santa Apolnia, Apartado 1172, 5301-855 Bragança, Portugal. Tel: 351 273303200; 351273331570; Fax: 351273325405; E-mail: joaos@ipb.pt

Olívia Rodrigues Pereira, Departamento of Diagnostic and Therapeutic Technology, School of Health, Polytechnic Institute of Bragança, Av. D. Afonso V, 5300-121 Bragança, Portugal, Tel: 351273303200; 351273331570; Fax: 351273325405; E-mail: oliviapereira@ipb.pt

Received date: September 26, 2017; Accepted date: October 06, 2017; Published date: October 13, 2017

Copyright: (c) 2017 Paula D. This is an open-access article distributed under the terms of the Creative Commons Attribution License, which permits unrestricted use, distribution, and reproduction in any medium, provided the original author and source are credited.

\begin{abstract}
Background: Currently, complementary and alternative medicine emerge as important therapies in the prevention and treatment of various health problems. In view of this, the present study aims to evaluate the efficacy of essential oils in reducing stress and anxiety levels in aromatherapy users, at a clinic of Bragança, Portugal.

Methods: A study was performed with 36 individuals divided in two distinct groups: "aroma group" and "control group". Individuals of "aroma group" were treated with a mixture of essential oils of Lavandula angustifolia Mill and Matricaria recutita $L$. applied with Effleurage massage while the individuals of "control group" received only Effleurage massage. Stress and anxiety levels of all individuals participating in the study were evaluated before and after the treatment. Additionally, the chemical composition of the essential oils was evaluated by GC and GC-MS.
\end{abstract}

Results: In the aromatherapy assay, the "aroma group" showed a significant decrease of $12 \%$ and $30 \%$, in stress and anxiety levels, respectively, in the "control group" this decrease was lower $(3.3 \%$ and $2.6 \%$ for stress and anxiety levels, respectively).

Conclusion: In this study, aromatherapy was effective in stress and anxiety levels reduction and linalool, the major compound of the essential oil mixture, may be positively contributing for these effects.

Keywords: Aromatherapy; Lavandula angustifolia Mill; Matricaria recutita L; Volatil oils; Stress disorders; Anxiety

\section{Introduction}

Natural products and particularly those from plants, are used by humans since ancient times with the purpose to relief and cure diseases or to maintain health [1]. Gradually the herbs and their essential oils became part of the prevention and treatment of diseases, particularly in situations where physicians frequently were not present, as in the case of rural areas. The use of medicinal plants for the treatment of various diseases was a common practice among the populations that resort to spontaneous plants due to easy local access $[2,3]$. The World Health Organization (WHO) recognizes several benefits in the use of complementary and alternative medicines (CAM) playing an important role in the treatment or prevention of chronic diseases and improving life quality [4,5]. One form of CAM, aromatherapy, comprises the use of essential oils as treatment, generally applied by inhalation, on the skin or, less frequently, orally. Today, aromatherapy is a form of treatment recognized by the WHO, commonly used to relieve pain, improve mood and promote a sense of relaxation and used for anxiety and daily stress problems [6].

The essential oils used in aromatherapy can have different origins, as they can be extracted from spontaneous plants or from cultivars, and their composition can vary with environmental factors, such as climatic and soil conditions $[7,8]$. Thus, it is very important to know the composition of the essential oils to compare and understand the relevance of the major compounds in the effects of aromatherapy. The essential oil of Lavandula ssp. is well known and has been described as having antibacterial, antifungal, sedative, carminative (smooth muscle relaxing) properties and antidepressant activity [9], which justifies its use in aromatherapy and as pharmacological agent [10]. Literature indicates Matricaria recutita $L$. essential oil as antispasmodic and anxiolytic agent [11] with moderate antioxidant and antimicrobial activities [12,13] and has been used as natural medicine and in aromatherapy since a long time. The aim of this study was to evaluate the effectiveness of essential oils used in aromatherapy in the reduction of stress and anxiety levels, by applying a mixture of essential oils (Matricaria recutita L. and Lavandula ssp.) through Effleurage massage technique. In addition, and in order to identify the compounds responsible for the effects, the chemical composition of the essential oils was determined.

\section{Materials and Methods}

\section{Collection of plants}

Plants of Matricaria recutita $L$. were collected in the wild at Montesinho Natural Park, during the flowering stage (July-August). Plants of Lavandula angustifolia Mill were collected in the gardens and 
greenhouses of Agrarian School of Bragança, between June and July. The species were identified and registration vouchers deposited in Herbarium of the Escola Superior Agrária of Bragança-BRESA. The extraction of essential oils by hydro distillation was performed using a Clevenger apparatus, for $3 \mathrm{~h}$, according to the European Pharmacopoeia [14], with yield determination (v/fresh weight). The essential oils were stored at $-20^{\circ} \mathrm{C}$ in the dark. From each essential oil, a small amount was used for the GC and GC-MS analyses and the remainder was used to prepare the mixtures for further use in the aromatherapy assays.

\section{Aromatherapy assay}

The data were collected using a questionnaire, composed by three sections. Section 1 was the perceived stress Cohen Perceived Stress Symptoms scale (1983) with 14 items [15]. Section 2 was composed of Hamilton Anxiety Rating scale (1959) [16] for measuring the anxiety levels. In section 3, generic questions were included about the perception and the use of aromatherapy and also sociodemographic questions. Section 1 and section 2 were applied to the participants before and after the aromatherapy or Effleurage massage treatments while section 3 was applied just before the treatments.

For the experimental part of the study, an opportunistic sample was used. Adults aged between 18 and 45 years, users of a clinic in Bragança, Portugal, with high levels of stress and with medium or severe anxiety were included in the study. This way, the inclusion criteria includes a stress level equal or greater than $75 \%$ and a minimum of 20 points on the anxiety scale. For the determination of the stress values it was used the Cohen Perceived Stress Symptoms scale (1983) [15] while the Hamilton Anxiety Rating scale (1959) [16] was used to determine the level of anxiety. Individuals with psychiatric conditions, pregnant women and individuals under any type of treatment for stress and anxiety were excluded from the study.

The 36 individuals of both sexes, aged between 18 and 45 years, included in the study. The participants, mostly of female gender $(83 \%$, $\mathrm{n}=30)$ with ages between 18 and $25(67 \%, \mathrm{n}=24)$, were divided into two distinct groups: "aroma group" ( $\mathrm{n}=18)$ and "control group" $(\mathrm{n}=18)$. "Aroma group" received a treatment with a mixture of the two essential oils (Lavandula angustifolia Mill and Matricaria recutita $L ; 60: 40 \mathrm{v} / \mathrm{v}$ ) using sweet almond oil as vector and Effleurage massage, while for "control group" only Effleurage massage with sweet almond oil, an odorless oil, was applied. The complete treatment of the two groups consisted of fourteen sessions (once a week) of thirty minutes each.The levels of stress and anxiety of the participants were assessed before and after treatment, in the two groups.

During this study, all ethical aspects were guaranteed. Before starting, all participants were informed about the aim of the study, the procedures and the voluntary nature of their participation. They were informed that a refusal or a termination of their participation would not have any negative consequence, being able to withdraw from the study at any time. All participants have signed the informed consent form and, to ensure confidentiality, a code for each participant was used instead of their names, and the collective disclosure of results was also guaranteed.

\section{Chemical analysis of essential oils}

Gas chromatography (GC): Gas chromatographic analyses were performed using a Perkin Elmer Autosystem XL (Perkin Elmer, Shelton, Connecticut, USA) gas chromatograph equipped with two flame ionization detectors (FIDs), a data handling system and a vaporizing injector port into which two columns of different polarities were installed: a DB-1 fused-silica column $(30 \mathrm{~m} \times 0.25 \mathrm{~mm}$ i.d., film thickness $0.25 \mu \mathrm{m}$ ) (J\&W Scientific Inc., Rancho Cordova, CA, USA) and a DB-17HT fused-silica column $(30 \mathrm{~m} \times 0.25 \mathrm{~mm}$ i.d., film thickness $0.15 \mu \mathrm{m})$ (J\&W Scientific Inc.). Oven temperature was programmed, $45^{\circ} \mathrm{C}$ to $175^{\circ} \mathrm{C}$, at $3^{\circ} \mathrm{C} / \mathrm{min}$, subsequently at $15^{\circ} \mathrm{C} / \mathrm{min}$ up to $300^{\circ} \mathrm{C}$, and then held isothermal for $10 \mathrm{~min}$; injector and detector temperatures, $280^{\circ} \mathrm{C}$ and $300^{\circ} \mathrm{C}$, respectively; carrier gas, hydrogen, adjusted to a linear velocity of $30 \mathrm{~cm} / \mathrm{s}$. The samples were injected using split sampling technique, ratio 1:50. The volume of injection was $0.2 \mu \mathrm{l}$ of a pentane-oil solution. The percentage composition of the oils was computed by the normalization method from the GC peak areas, calculated as mean values of two injections from each essential oil, without using correction factors.

Gas chromatography-mass spectrometry (GC-MS): The GC-MS unit consisted of a Perkin. Elmer Autosystem XL (Perkin Elmer, Shelton, Connecticut, USA) gas chromatograph, equipped with DB-1 fused-silica column $(30 \mathrm{~m} \times 0.25 \mathrm{~mm}$ i.d., film thickness $0.25 \mu \mathrm{m})$ (J \& W Scientific, Inc.), and interfaced with a Perkin-Elmer Turbomass mass spectrometer (software version 4.1, Perkin Elmer, Shelton, Connecticut, USA). Injector and oven temperatures were as above; transfer line temperature, $280^{\circ} \mathrm{C}$; ion trap temperature, $220^{\circ} \mathrm{C}$; carrier gas, helium, adjusted to a linear velocity of $30 \mathrm{~cm} / \mathrm{s}$; split ratio, 1:40; ionization energy, $70 \mathrm{eV}$; ionization current, $60 \mu \mathrm{A}$; scan range, $40 \mathrm{amu}$ to $300 \mathrm{amu}$; scan time, $1 \mathrm{sec}$. The identity of the components was assigned by comparison of their retention indices, relative to $\mathrm{C}_{9}$ and $\mathrm{C}_{17} \mathrm{n}$-alkane indices and GC-MS spectra from a homemade library, constructed based on the analyses of reference oils, laboratorysynthesized components and commercial available standards.

Statistical analysis: The results were analyzed using the SPSS program (version 20) and the descriptive statistics expressed as mean, standard deviation and percentage. For statistic comparison the Wilcoxon and Mann-Whitney $U$ tests have been used with a level of significance of $5 \%$ ( $\mathrm{p}$-value $<0.05)$.

\section{Results}

Regarding the levels of stress and anxiety in each group, there are statistically significant differences between the initial and final values of stress and anxiety of the two groups (Table 1). In the "aroma group" it was verified that the values distribution of "stress initial" and "stress final" are not identical. Similar results have been found for anxiety, with values of "anxiety initial" and "anxiety final" not identical.

For the "control group" the distributions of the values of the variables "stress initial" and "stress final" are not identical and similar results have been found for "anxiety initial" and "anxiety final" values (Table 1). In the "aroma group" it was evident a decrease in the stress levels (12\%) and anxiety (30\%) after the treatment, from a rating "high" to "medium", compared to the "control group" while the levels of stress and anxiety have decreased of $3.3 \%$ and $2.6 \%$, respectively. In this way, in the "aroma group" it was observed that anxiety levels decreased more intensively than stress levels.

Further, with regard to differences between the initial and final values of stress and anxiety levels, after individual and group analysis, a significant decrease of $6.7 \%$ and 7.2 points it was observed for stress and anxiety levels, respectively (Table 2). Moreover, it is important to note that the differences between initial and final values were greater in the "aroma group". 


\begin{tabular}{|l|l|l|l|l|l|l|l|l|}
\hline \multicolumn{4}{|l|}{ Aroma Group $(\mathbf{n}=\mathbf{1 8})$} & \multicolumn{2}{l|}{ Control Group $(\mathbf{n}=18)$} \\
\hline Variables & Initial & Final & Test Values & $\mathbf{p}$-value & Initial & Final & Test Values & p-value \\
\hline $\begin{array}{l}\text { Stress } \\
(\%)\end{array}$ & $77.4 \pm 3.5$ & $68.3 \pm 7.2$ & -3.731 & $<0.001$ & $72.7 \pm 2.8$ & $70.28 \pm 2.7$ & -3.52 & $<0.001$ \\
\hline Anxiety (points) & $25.3 \pm 7.6$ & $17.7 \pm 7.9$ & -3.29 & $<0.001$ & $17.17 \pm 2.0$ & $16.72 \pm 2.0$ & -2.53 & 0.011 \\
\hline The levels of stress e anxiety initial and final are expressed as average \pm standard deviation; Values of the test and p-value of Wilcoxon test. \\
\hline
\end{tabular}

Table 1: Initial and final levels of stress and anxiety.

\begin{tabular}{|c|c|c|c|c|}
\hline \multirow{2}{*}{ Variables } & Aroma & Control & \# Groups & \multirow{2}{*}{ p-value } \\
\hline & Group ( $n=18)$ & Group (n=18) & average & \\
\hline Stress (\%) & $9.2 \pm 6.9$ & $2.4 \pm 1.6$ & 6.7 & $<0.001$ \\
\hline Anxiety(points) & $7.7 \pm 8.1$ & $0.4 \pm 0.6$ & 7.2 & $<0.001$ \\
\hline
\end{tabular}

Table 2: Initial and final values of stress and anxiety levels.

Concerning aromatherapy treatment, the majority of participants were satisfied (67\%) and $22 \%$ were totally satisfied. In agreement with this, when questioned about the benefits of aromatherapy, most participants agreed that aromatherapy has health benefits, namely, it is useful $(83 \%)$, promotes health $(86 \%)$, is effective in preventing disease (86\%), promotes well-being and quality of life (69\%) and promotes a good relationship between the therapist and the client (83\%).

Accordingly, $70 \%$ of the participants agreed with the inclusion of aromatherapy in the National Health Service, due to the following reasons (with percentages of response between $94 \%$ to $100 \%$ ): lack of confidence in conventional medicine, less adverse effects by using natural products, efficient prevention of disease and low cost treatment.

Is important to highlight that is a study with some limitations mainly due the sample size and non-probability sampling used. The small sample size and their non-random selection limit the extrapolation of the results to the population. In accordance to that, the degree to the aromatherapy effect of the individuals of the sample differs from the population is unknown.

Additionally, there may have been subjects who might be left out during the selection process and individuals who are over-represented in the sample. In conclusion, the results obtained in the aromatherapy assays indicate positive effects in the control of stress and anxiety for the sample studied, however it must be confirmed in further studies.

The essential oils of Lavandula angustifolia and Matricaria recutita, were obtained with a yield of $3.5 \%$ and $0.41 \%$ ( $\mathrm{v} /$ fresh weight), respectively. The composition of the essential oils of Lavender, of Chamomile and of the mixture used in the aromatherapy assay is shown in Table 3, considering only the major compounds $(\geq 2 \%)$.

For Lavender essential oil, with a percentage of identification near $99 \%$, the more abundant compounds were linalool, camphor, 1,8cineole, terpinen-4-ol, borneol and cis- $\beta$-ocimene. Although with a lower percentage of identification (approximately 50\%) for
Chamomile, the main compounds were 1,8-cineole, pinocarvone, trans-pinocarveol, hexyl angelate, $\alpha$-pinene and isobutyl isobutyrate.

It is noteworthy the different profile of the two essential oils with some compounds present in the essential oil of only one of the plant species while others are common to both plant species essential oils, but frequently with clearly quantitative differences (e.g. linalool and terpinen-4-ol).

\begin{tabular}{|l|l|l|l|l|}
\hline Components & RI & Lavender & Chamomile & Mixture \\
\hline a-Pinene & 930 & 0.6 & 3.8 & 1.9 \\
\hline Isobutyl isobutyrate & 999 & - & 2.6 & 0.3 \\
\hline $1,8-C i n e o l e$ & 1005 & 7.5 & 13.9 & 12.2 \\
\hline Limonene & 1009 & 1.3 & - & 2 \\
\hline cis-B-Ocimene & 1017 & 5 & - & 4.1 \\
\hline Linalool & 1074 & 45.1 & 0.5 & 43.4 \\
\hline Camphor & 1102 & 8.6 & 0.3 & 8.2 \\
\hline trans-Pinocarveol & 1106 & - & 4.7 & - \\
\hline Pinocarvone & 1121 & - & 7.8 & 1.3 \\
\hline Borneol & 1134 & 5.5 & - & 4.8 \\
\hline Terpinen-4-ol & 1148 & 7 & 0.6 & 2.3 \\
\hline Linalyl acetate & 1245 & 2.9 & - & - \\
\hline Hexyl angelate & 1273 & - & 3.9 & . \\
\hline *RI: Retention Index relative to $\mathrm{C}_{9}$ and $\mathrm{C}_{17} \mathrm{n}$-alkanes on the DB-1 column \\
\hline
\end{tabular}

Table 3: Major compounds ( $\geq 2 \%$ ) in the essential oils of Lavender, Chamomile and their mixture. 


\section{Discussion}

The results indicated that aromatherapy is an effective treatment in the reduction of stress and anxiety levels. Specifically, the "aroma group" showed a significant decrease of $12 \%$ and $30 \%$, with respect to stress and anxiety compared to the control group in which a minor decline in these levels ( $3 \%$ in stress and $2.6 \%$ in anxiety) was observed. The differences in stress and anxiety levels between aroma and control groups before and after treatment were also significant.

The essential oils analyses allow to found compounds such as linalool, 1,8 cineole in Lavandula. As described in the literature, the essential oil of this plant is mostly composed by oxygen-containing monoterpenes compounds [17]. Although the composition of the essential oil of Lavandula angustifolia shows a remarkable variability, depending on the source, the season or the method of isolation [18-22], the main constituents are predominantly linalool, 1,8-cineole or linalyl acetate, and oxygenated monoterpenes constitute, largely, the major group. A recent publication showed that the essential oil of Lavender and its main constituent, linalool, have a potential inhibitory effect on neuronal spontaneous electrical activity, using rat neuronal networks [20]. Similar studies have demonstrated the benefit of aromatherapy in stress control in primary school teachers [23] and nurses [24]. Additionally, various studies have shown that aromatherapy reduces anxiety in surgical patients $[25,26]$.

To clarify the aromatherapy regarding the effectiveness, it is important the increase of research in this area [27,28]. In addition, the monitoring and reporting of possible side effects should be done to ensure the safety of this technique $[29,30]$.

A comprehensive view of the actual position of these participants in relation to aromatherapy has been collected, which recommended the inclusion of this therapy in National Health Service. The European Information Centre for Complementary \& Alternative Medicine highlight the remarkable growth of these practices in the last ten years, meeting the recommendation that patients may have more choice outside the scope of conventional medicine $[27,31,32]$.

\section{Conclusion}

Although the study showed the importance of aromatherapy in the reduction of stress and anxiety levels, more research is needed to understand which compounds are involved and the mechanism of action related to each essential oil used.

\section{Acknowledgements}

The authors gratefully acknowledge the financial support provided by Fundação para a Ciência e a Tecnologia (FCT) under UID/AMB/ 50017/2013, FEDER PT2020-Compete 2020. Authors are also grateful to Gabinete Terapêutico Telmo Teles, Unipessoal, Lda, Bragança, for the availability to perform the aromatherapy assay.

\section{References}

1. Mukherjee PK, Venkatesh M, Gantait A (2010) Ayurveda in modern medicine: Development and modification of bioactivity. In: Mander L, Liu HW. Comprehensive natural products II. Hardbound: Elsevier, USA. pp: 479-507.

2. Salgueiro J (2005) Herbs, uses and knowledge - Medicinal plants in Alentejo and other natural products. Edições Colibri. Lisboa, Portugal.
3. Cunha AP, Teixeira F, Silva AP, Roque OR (2010) Plants in therapeutics Pharmacology and clinical trials. Calouste Gulbenkian Foundation, Lisboa, Portugal.

4. WHO (2002) Traditional medicine strategy 2002-2005, World Health Organization. Geneva, 1-3.

5. World Health Organization (WHO) (2002) Launches the first global strategy on traditional and alternative medicine.

6. Cunha AP, Nogueira MT, Roque OR (2012) Aromatic plants and essential oils-composition and applications. Calouste Gulbenkian Foundation. Lisboa, Portugal.

7. Aghaei Y, Mirjalili MH, Nazeri V (2013) Chemical diversity among the essential oils of wild populations of Stachys lavandulifolia vahl (Lamiaceae) from Iran. Chem Biodivers 10: 262-273.

8. Maissa BJ, Walid H (2014) Antifungal activity of chemically different essential oils from wild Tunisian Thymus spp. Nat Prod Res. 29: 869-873.

9. Cavanagh HMA, Wilkinson JM (2002) Biological activities of lavender essential oil. Phytother Res 16: 301-308.

10. Ulbricht C, Basch E, Foppa I, Liebowitz R, Nelson J, et al. (2004) Thyme (Thymus vulgaris L.), Thymol. J Herb Pharmacother 4: 63-78.

11. McKay DL, Blumberg JB (2006) A review of the bioactivity and potential health benefits of Chamomile tea (Matricaria recutita L.) Phytother Res 20: 519-530.

12. Zargaran A, Borhani-Haghighi A, Faridi P, Daneshamouz S, Kordafshari G, et al. (2014) Potential effect and mechanism of action of topical chamomile (Matricaria chammomila L.) oil on migraine headache: A medical hypothesis. Med Hypotheses 83: 566-569.

13. Agatonovic-Kustrin S, Morton DW, Yusof AP (2015) Thin-Layer Chromatography-bioassay as powerful tool for rapid identification of bioactive components in botanical extracts. Mod Chem appl 3:e120.

14. Council of Europe (COE) (2007) European directorate for the quality of medicines. European Pharmacopoeia 6th Edition. Strasbourg, France.

15. Cohen S, Kamarck T, Mermelstein R (1983) A global measure of perceived stress. J Health Soc Behav 24: 385-396.

16. Hamilton M (1959) The assessment of anxiety states by rating. Br J Med Psychol 32: 50-55.

17. Setzer WN (2009) Essential oils and anxiolytic aromatherapy. Nat Prod Commun 4: 1305-1316.

18. Singh O, Khanam Z, Misra N, Srivastava MK (2011) Chamomile (Matricaria chamomilla L.): An overview. Pharmacogn Rev 5: 82-95.

19. Lakusic B, Lakusic D, Ristic M, Marcetic M, Slavkovska V (2014) Seasonal variations in the composition of the essential oils of Lavandula angustifolia (Lamiacae). Nat Prod Commun 9: 859-862

20. Caputo L, Souza LF, Alloisio S, Cornara L, De Feo V (2016) Int J Mol Sci 17:1999.

21. Carrasco A, Martinez-Gutierrez R, Tomas V, Tudela J (2016) Lavandula angustifolia and Lavandula latifolia Essential Oils from Spain: Aromatic Profile and Bioactivities. Planta Med. 82: 163-170.

22. Chrysargyris A, Panayiotou C, Tzortzakis N (2016) Nitrogen and phosphorus levels affected plant growth, essential oil composition and antioxidant status of lavender plant (Lavandula angustifolia Mill.) Ind Crops Prod 83: 577-586.

23. Liu SH, Lin TH, Chang KM (2013) The physical effects of aromatherapy in alleviating work-related stress on elementary school teachers in Taiwan Evid Based Complement Alternat Med 853809.

24. Chen MC, Fang SH, Fang L (2013) The effects of aromatherapy in relieving symptoms related to job stress among nurses. Int J Nurs Pract 21: 87-93.

25. Ni CH, Hou WH, Kao CC, Chang ML, Yu LF, et al. (2013) The anxiolytic effect of aromatherapy on patients awaiting ambulatory surgery: a randomized controlled trial. Evid Based Complement Alternat Med 927419.

26. Fayazi S, Babashahi M, Rezaei M (2011) The effect of inhalation aromatherapy on anxiety level of the patients in preoperative period. Iran J Nurs Midwifery Res 16: 278-283. 
Citation: Paula D, Luís P, Olívia RP, João SM (2017) Aromatherapy in the Control of Stress and Anxiety. Altern Integr Med 6: 248. doi: 10.4172/2327-5162.1000248

Page 5 of 5

27. Coulter ID, Willis EM (2004) The rise and rise of complementary and alternative medicine: A sociological perspective. Med J Aust 180: 587-589.

28. National Center for Complementary and Alternative Medicine (NCCAM) (2008) CAM Basics.

29. Heck AM, Lukes AL, Dewitt BA (2000) Potential interactions between alternative therapies and warfarin. Am J Health Syst Pharm. 57, 1221-1227.

30. Lim AN, Cranswich N, South M (2010) Adverse events associated with the use of complementary and alternative medicine in children. Arch Dis Child 96: 297-300.
31. Olver I (2012) Complementary and Alternative Medicines - The introductory perspective, in: Perspectives on complementary and alternative medicines, Olver I, and Robotin M. eds., Imperial College Press, London.

32. Bann CM, Walsh EG, Sirois FM (2010) Complementary and alternative medicine use and benefit finding among cancer patients. J Altern Complement Med 16: 745-752. 